\title{
Severe lateral sinus thrombosis during the postpartum period that required decompressive craniectomy
}

\author{
Tokunori Kanazawa ำ , Kosuke Karatsu, Takumi Kuramae, Masayuki Ishihara
}

Department of Neurosurgery, National Hospital Organization Tochigi Medical Center, Utsunomiya, Japan

Correspondence to Dr Tokunori Kanazawa; norinori0128jp@yahoo.co.jp

Accepted 23 July 2021

\section{DESCRIPTION}

A 34-year-old woman presented to our unit with severe headache and nausea 18 days after a caesarean section. Her medical history included an epidural anaesthesia for vaginal delivery and a recent general anaesthesia for caesarean section, with no history of coagulopathy. Clinical examination revealed no limb paralysis. A routine laboratory examination revealed high levels of fibrinogen $(615.0 \mathrm{~g} / \mathrm{L})$ and D-dimer $(8.4 \mathrm{mg} / \mathrm{L})$. No characteristic was observed in the thrombophilia screening and rheumatoid factors of the patient. Initially, head CT revealed subarachnoid haemorrhage in the posterior cranial fossa and mild cerebral oedema in the left cerebellar hemisphere (figure 1A). According to the patient's age and medical history, urgent cerebral digital subtraction angiography was performed to rule out diseases such as cerebral aneurysms, sinus thrombosis and arteriovenous malformations. We

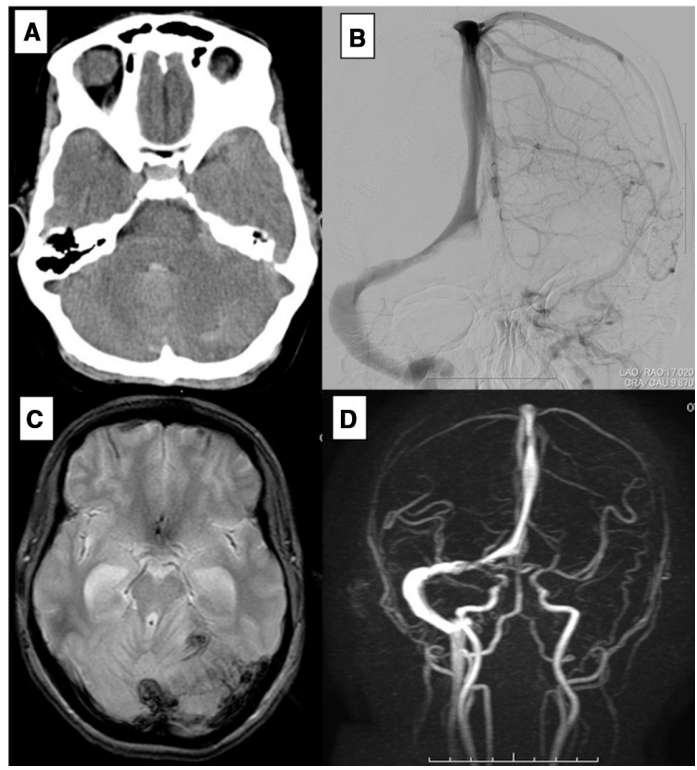

Figure 1 (A) Cranial CT on admission shows a subarachnoid haemorrhage with blood in the fourth ventricle. (B) Cerebral digital subtraction angiography with contrast medium injection of the left internal carotid artery. This posterior-anterior venous phase projection shows a thrombotic occlusion of the left transverse and sigmoid sinus, with non-occlusive thrombus in the right transverse sinus. (C) T2 star-weighted imaging on admission shows thrombus in the left transverse sinus. (D) Magnetic resonance venography on admission also shows a thrombotic occlusion of the left transverse and sigmoid sinus. found a left transverse and sigmoid sinus thrombosis (figure 1B). T2 star-weighted imaging and magnetic resonance venography also revealed a cerebral venous and sinus thrombosis (CVST) involving the left lateral sinus (figure 1C,D); therefore, a presumptive diagnosis of lateral sinus thrombosis during the postpartum period was made. She was, therefore, treated with intravenous administration of unfractionated (standard) heparin and glycerol. Dosing of heparin was adjusted to maintain the activated partial thromboplastin time prolonged at 1.5-2.5 times the normal laboratory control. One day after admission, she had a sudden change in consciousness (Glasgow Coma Scale (GCS) 11: E2V4M5). Head CT showed acute hydrocephalus due to progressive cerebellar brain oedema (figure 2A), and external ventricular drainage was performed. However, 1 day later, her level of consciousness deteriorated significantly, and head CT revealed prominent brain swelling in the left

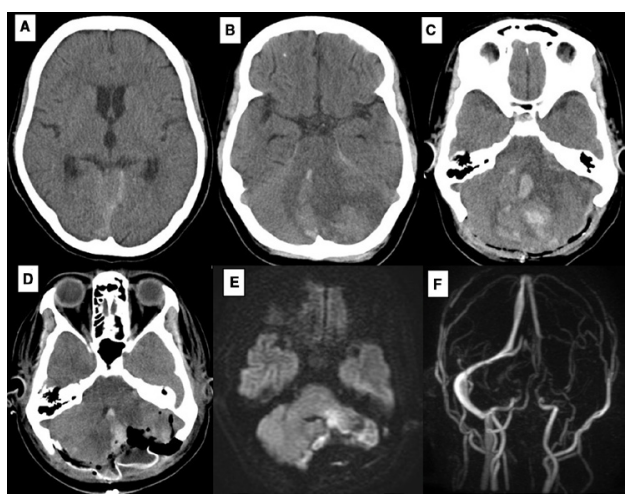

Figure 2 (A) Cranial CT before external ventricular drainage (first operation) shows ventricular enlargement. (B) Cranial CT before the decompressive craniectomy of the posterior fossa (second operation). The fourth ventricle and the cisterns of the posterior fossa are compressed because of brain swelling in the left cerebellar hemisphere. (C) Cranial CT after the decompressive craniectomy of the posterior fossa (second operation). The fourth ventricle and the cisterns of the posterior fossa are still compressed. (D) Cranial CT after partial resection of the left cerebellar hemisphere (third operation). The fourth ventricle is now reopened. (E) Diffusion-weighted imaging at 1 month after admission shows no brainstem damage due to compression. (F) Magnetic resonance venography at 1 month after admission still shows a thrombotic occlusion of the left transverse and sigmoid sinus. Recanalisation was not achieved. 
cerebellar hemisphere (figure 2B). An emergency decompressive craniectomy with duroplasty was performed (figure 2C). During the second operation, the left transverse sinus was opened, and surgical thrombectomy was performed (not shown in the figure). After the second operation, intracranial pressure was uncontrolled, followed by additional partial resection of the left cerebellar hemisphere (figure 2D). Two days after the third operation, systemic heparinisation was restarted. Her mental state gradually improved from coma to lethargy. Finally, she recovered to E4V5M6 on GCS and was discharged to a rehabilitation centre. On follow-up MRI 1 month after admission, the brainstem remained intact (figure 2E). At 6-month follow-up, she had a modified Rankin Scale score of 2 with truncal ataxia.

CVST is a rare occurrence ${ }^{1}$ but a life-threatening neurological emergency during pregnancy and puerperium. The early postpartum period and caesarean section are known risk factors for the development of CVST. ${ }^{23}$ In this case, an emergency surgical decompressive craniectomy had to be performed as the ultimate procedure in CVST refractory to medical therapy to prevent progressive brain swelling, brainstem compression and obstructive hydrocephalus, which could have led to fatality. Previous reports have demonstrated the feasibility of decompressive hemicraniectomy in selected patients with CVST involving the lateral sinus. ${ }^{45}$ To our knowledge, the parenchymal lesion due to a lateral sinus thrombosis was mainly located supratentorially, and an infratentorial lesion is extremely rare. This unique case supports decompressive craniectomy as life-saving in postpartum women with an infratentorial lesion due to CVST.

Appropriate treatment for CVST is still controversial; however, heparin and subsequent long-term oral anticoagulation have been reported as a safe and effective treatment. ${ }^{67}$ In most neurovascular centres, the current therapy escalation for patients with severe sinus thrombosis today is systemic heparinisation, endovascular thrombectomy (ie, rheolysis) and decompressive craniectomy. If endovascular thrombectomy of the occluded venous sinus(es) fails or if the brain congestion increases despite sinus recanalisation, decompressive craniectomy is the last resort. In this case, her condition permitted no delay in performing decompressive craniectomy, and endovascular thrombectomy was not considered. However, we tried surgical thrombectomy during the emergency decompressive craniectomy although recanalisation was not achieved on follow-up MRI at 1 month after admission (figure 2F). Finally, the patient recovered successfully with surgical decompression and anticoagulants.
Patient's perspective

Husband: 'We were informed and agreed that my wife had cerebellar haemorrhagic infarction due to CVST and underwent repeated operations. We were relieved to confirm improvement in symptoms. After discharge, she was fine and continued to try her best with rehabilitation'.

\section{Learning points}

- Cerebral venous and sinus thrombosis is a rare but lifethreatening disorder in pregnant and postpartal women.

- MRI including venous time of flight or phase-contrast angiography is the diagnostic modality of choice.

- The therapeutic escalation scheme starts with heparinisation, followed by endovascular thrombectomy and surgical decompressive craniectomy-if needed.

Contributors Study concept or design, data collection, data analysis or interpretation and writing the paper: TKa. Management of this patient: KK and TKa. Supervisor: TKu and MI.

Funding The authors have not declared a specific grant for this research from any funding agency in the public, commercial or not-for-profit sectors.

Competing interests None declared.

Patient consent for publication Obtained.

Provenance and peer review Not commissioned; externally peer reviewed.

ORCID iD

Tokunori Kanazawa http://orcid.org/0000-0002-6191-1209

\section{REFERENCES}

1 Ferro JM, Aguiar de Sousa D. Cerebral venous thrombosis: an update. Curr Neurol Neurosci Rep 2019;19.

2 Bajko Z, Motataianu A, Stoian A, et al. Postpartum cerebral venous Thrombosis-A single-center experience. Brain Sci 2021;11:327-9.

3 Silvis SM, Lindgren E, Hiltunen $\mathrm{S}$, et al. Postpartum period is a risk factor for cerebral venous thrombosis. Stroke 2019:50:501-3.

4 Zeng L, Derex L, Maarrawi J, et al. Lifesaving decompressive craniectomy in 'malignant' cerebral venous infarction. Eur J Neurol 2007;14:e27-8.

5 Stefini R, Latronico N, Cornali C. Emergent decompressive craniectomy in patients with fixed dilated pupils due to cerebral venous and dural sinus thrombosis: report of three cases. Available: https://academic.oup.com/neurosurgery/article/45/3/626/2838563

6 Caprio F, Bernstein RA. Duration of anticoagulation after cerebral venous sinus thrombosis. Neurocrit Care 2012;16:335-42.

7 Stam J. Thrombosis of the cerebral veins and sinuses, 2005. Available: https://www. nejm.org/

Copyright 2021 BMJ Publishing Group. All rights reserved. For permission to reuse any of this content visit

https://www.bmj.com/company/products-services/rights-and-licensing/permissions/

BMJ Case Report Fellows may re-use this article for personal use and teaching without any further permission.

Become a Fellow of BMJ Case Reports today and you can:

- Submit as many cases as you like

- Enjoy fast sympathetic peer review and rapid publication of accepted articles

- Access all the published articles

- Re-use any of the published material for personal use and teaching without further permission

Customer Service

If you have any further queries about your subscription, please contact our customer services team on +44 (0) 2071111105 or via email at support@bmj.com.

Visit casereports.bmj.com for more articles like this and to become a Fellow 